\title{
Study on Coefficient of Permeability of Copper slag when admixed with Lime and Cement
}

\author{
C.Lavanya ${ }^{1}$, A. Sreerama Rao ${ }^{2}$, N. Darga Kumar ${ }^{3}$ \\ ${ }^{1}$ Department of Civil Engineering, GRIET, Hyderabad, Andhra Pradesh, India, \\ ${ }^{2}$ Formerly Principal JNTU, Kakinada, Andhra Pradesh, India, \\ ${ }^{3}$ Department of Civil Engineering, JNTUH, Hyderabad, Andhra Pradesh, India,
}

\begin{abstract}
Production of waste in unpredictable amounts is almost in every part of metal and non metal casting trade. These wastes can be converted to material goods if processed for vital improvement of valuables provided it is cost-effective. Random dumping of these wastes may lead to environmental problems and therefore, presently the reuse of the waste materials in various fields is seen for fairly various periods. Copper slag is a waste product generated during the smelting process for the production of copper. It has been estimated that for every tonne of copper produced, about 1.8-2.2 tonnes of copper slag is generated as a waste. Due to increase in production capacity of copper, copper slag getting accumulated require additional dumping space and causing wastage of good cultivable land. The present paper discusses the laboratory test results of coefficient of permeability tests conducted on copper slag mixed with cement and lime. The copper slag mixed with lime and cement in various percentages were kept for curing and then tested after 7, 14, 28 days. Effective results were observed for the coefficient of permeability of copper slag on addition of lime and cement from $0 \%$ to $10 \%$. There is a decrease in coefficient of permeability value as the percentage of addition of lime and cement increases and with the curing period. The coefficient of permeability is very high for copper slag alone. When copper slag is mixed with a binding material like lime or cement, there is a reduction in permeability. Also upon mixing the same with an expansive soil, it may be suitable to reduce the swelling characteristics by developing pozzolanic reactions.
\end{abstract}

Keywords: Cement, Copper Slag, Lime, Permeability, Sample curing.

\section{Introduction}

Pure copper is rarely found in nature, but is usually combined with other chemicals in the form of copper ores. The process of extracting copper from copper ore varies according to the type of ore and the desired purity of the final product. Once the waste materials have been physically removed from the ore, the remaining copper concentrate must undergo several chemical reactions to remove the iron and sulphur. This process is called smelting. The recovery of sulphuric acid from the copper smelting process not only provides a profitable by-product, but it also significantly reduces the air pollution caused by the furnace exhaust. Copper slag is a waste product which comes out from the smelting process.

It has been estimated that the production of one tonne of blister copper generates 2.2 tonnes of slag. Metal industry slag, mine stone and mining waste are generally suitable for recycling or reuse and the use of these inorganic wastes as alternative materials in building, road and geotechnical applications have been reported $[1,2,3,4,5,6]$.

Upon mixing with problematic soil, Copper slag can be used as an efficient stabilizing cause for the upgrading of soils for use in highway embankments, sub-grades and sub-bases. Also, by mixing it with fly ash, it becomes suitable for embankment fill material. Slag, when mixed with fly ash and lime, develops pozzolanic reactions [7]. Fly ash has been widely accepted as embankment and structural fill material [8, 9].

Copper slag along with binding material or an admixture can be used as an alternative material to that of sand in road construction. If the copper slag is mixed with calcium-based compound like lime, the silica and alumina present in copper slag may react chemically on hydration and it may be used for the improvement of sub-grades and sub-bases. The present paper discusses the coefficient of permeability of the copper slag when admixed with cement and lime with varying percentages added and tested after 7, 14 and 28 days of curing period. 


\section{Experimental Work}

\subsection{Materials used in the present work}

\subsubsection{Copper Slag}

Copper slag was collected from Sterilite Industries, Tuticorin, Tamil Nadu, India. The physical and chemical properties are presented in Tables 1 and 2 respectively.

Table 1: Physical Properties of Copper Slag

\begin{tabular}{|c|c|}
\hline Property & Value \\
\hline Hardness, Moh's Scale & $6.5-7.0$ \\
\hline Specific Gravity & Non-Plastic \\
\hline Plasticity Index & Non-Swelling \\
\hline Swelling Index & Angular, Sharp edges \\
\hline Granule Shape & 1 \\
\hline Grain Size Analysis & 98.9 \\
\hline Gravel/Size (\%) & 0.05 \\
\hline Sand/Size (\%) & 23.5 \\
\hline Silt \& Clay/Sizes $(\%)$ & 6 \\
\hline MDD (kN/m $\left.{ }^{3}\right)$ & -- \\
\hline OMC (\%) & 0 \\
\hline Direct Shear test & 40 \\
\hline Cohesion (kN/m $\left.{ }^{2}\right)$ & $15.43 \times 10^{-3}$ \\
\hline Angle of internal friction (degree) & 3.5 \\
\hline Permeability $(\mathrm{cm} / \mathrm{sec})$ & \\
\hline CBR $(\%)$ & \\
\hline
\end{tabular}

Table 2: Chemical Composition of Copper Slag

\begin{tabular}{|c|c|}
\hline Property & $(\% \mathrm{wt})$ \\
\hline Iron Oxide, $\mathrm{Fe}_{2} \mathrm{O}_{3}$ & $55-60$ \\
\hline Silica, $\mathrm{SiO}_{2}$ & $28-30$ \\
\hline Aluminium Oxide, $\mathrm{Al}_{2} \mathrm{O}_{3}$ & $1-3$ \\
\hline Calcium Oxide, $\mathrm{CaO}$ & $3-5$ \\
\hline Magnesium Oxide, $\mathrm{MgO}$ & $1.0-1.5$ \\
\hline
\end{tabular}

\subsubsection{Cement and Lime}

Locally accessible cement and hydrated lime are used for the current study lime consists of $95 \%$ of Calcium hydroxide is used in the present study.

\subsection{Tests Conducted}

Variable head permeability tests were conducted [10] for the copper slag mixed with cement and lime separately of $2 \%, 4 \%, 6 \%, 8 \%$ and $10 \%$. Copper slag with admixture (cement and lime) is mixed in various percentages in dry condition and then water is added as per optimum moisture content. The samples are kept for curing for 7 days, 14 days and 28 days. After the curing period the copper slag mixed admixture is tested for the coefficient of permeability.

\subsubsection{Test Procedure}

Permeability is a property of a porous material which permits passage of fluids through interconnecting conditions. Permeability is defined as the rate of flow of water under laminar conditions through a unit cross-sectional area perpendicular to the direction of flow through a porous medium under unit hydraulic gradient and under standard temperature conditions. Coefficient of permeability is used to assess drainage characteristics of specimen, to predict rate of settlement founded on soil bed. In the present test coefficient of permeability of copper slag mixed with admixture is tested to study its behaviour. Future scope is to mix the copper slag along with admixture to the problematic soil and to study its behaviour in terms of coefficient of permeability of the soil specimen.

Sample of respective is prepared and water is mixed to optimum moisture content determined. De-aired water is preferred. During the test there should be no volume change in the soil, there should be no compressible air present in the voids of sample and the sample should be completely saturated. Inlet nozzle of the mould is connected to the stand pipe. Allow some water such that the flow is laminar and steady flow is obtained. Note down the time interval $t$ for a fall of head in the stand pipe $h$. Repeat the same three times to determine $t$ for the same head. The coefficient of permeability is determined by using the below equation.

$$
\mathrm{k}=\left(2.3 * \mathrm{a} * \mathrm{~L} *\left(\log \mathrm{h}_{1} / \mathrm{h}_{2}\right)\right) / \mathrm{A} * \mathrm{t}
$$

Where $\mathrm{k}=$ coefficient of permeability, $\mathrm{a}=$ area of stand pipe, $\mathrm{L}=$ Length of specimen, $h=$ height of fall from $h_{2}$ to $h_{2}, A=$ Area of the specimen, $t=$ time taken for the fall. 


\subsection{Permeability Test Results}

\section{Results and Discussion}

Variable head permeability tests were conducted on the copper slag samples mixed with cement and lime separately in various proportions of $2 \%, 4 \%, 6 \%, 8 \%$ and $10 \%$ after 7 days, 14 days and 28 days of curing period. Coefficient of permeability for the copper slag alone is reported as very high. The results of the tests conducted were presented below.

Table 3: Coefficient of Permeability values of Copper Slag when mixed with various \% of Lime after curing for 7 days, 14 days and 28 days

\begin{tabular}{|c|c|c|c|}
\hline $\begin{array}{c}\text { \% of Lime in } \\
\text { copper slag }\end{array}$ & 7 Days Curing & 14 Days Curing & 28 Days Curing \\
\hline 2 & $5.85 \times 10^{-3}$ & $5.37 \times 10^{-3}$ & $5.08 \times 10^{-3}$ \\
\hline 4 & $2.22 \times 10^{-3}$ & $2.01 \times 10^{-3}$ & $2.05 \times 10^{-3}$ \\
\hline 6 & $1.3 \times 10^{-3}$ & $1.28 \times 10^{-3}$ & $1.08 \times 10^{-3}$ \\
\hline 8 & $1.19 \times 10^{-3}$ & $1.08 \times 10^{-3}$ & $0.96 \times 10^{-3}$ \\
\hline 10 & $1.05 \times 10^{-3}$ & $0.74 \times 10^{-3}$ & $0.32 \times 10^{-3}$ \\
\hline
\end{tabular}

Table 4: Coefficient of Permeability values of Copper Slag when mixed with various \% of Cement after curing for 7 days, 14 days and 28 days

\begin{tabular}{|c|c|c|c|}
\hline $\begin{array}{c}\text { \% of Cement } \\
\text { in copper slag }\end{array}$ & 7 Days Curing & 14 Days Curing & 28 Days Curing \\
\hline 2 & $4.71 \times 10^{-3}$ & $3.79 \times 10^{-3}$ & $3.26 \times 10^{-3}$ \\
\hline 4 & $2.85 \times 10^{-3}$ & $2.68 \times 10^{-3}$ & $2.65 \times 10^{-3}$ \\
\hline 6 & $1.19 \times 10^{-3}$ & $1.17 \times 10^{-3}$ & $1.12 \times 10^{-3}$ \\
\hline 8 & $1.15 \times 10^{-3}$ & $1.01 \times 10^{-3}$ & $0.94 \times 10^{-3}$ \\
\hline 10 & $0.96 \times 10^{-3}$ & $0.66 \times 10^{-3}$ & $0.29 \times 10^{-3}$ \\
\hline
\end{tabular}

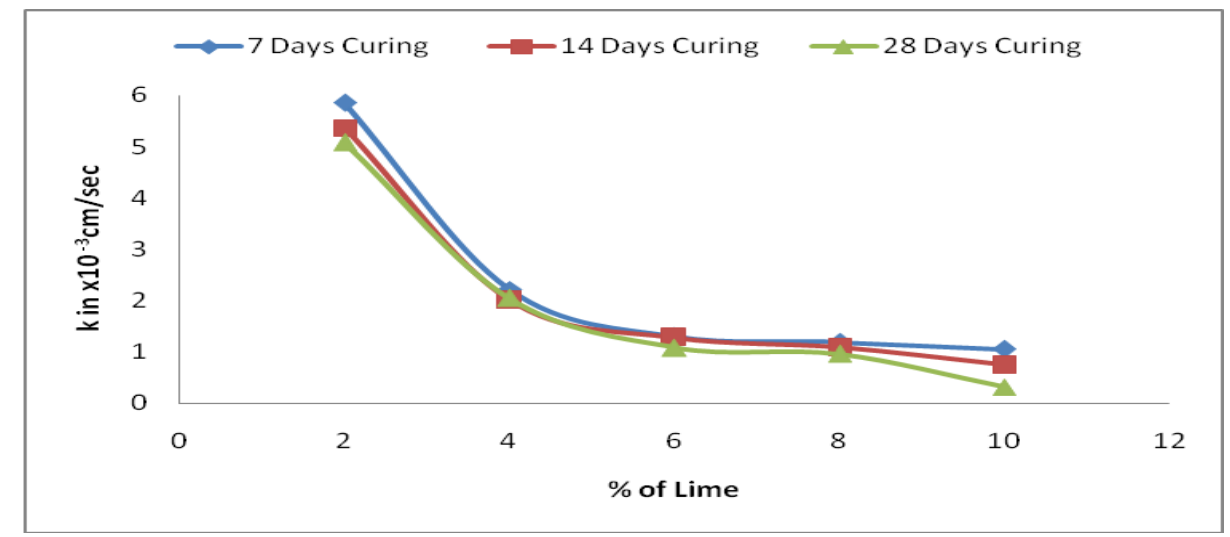

Fig. 1 Test results of Coefficient of Permeability for various \% of Lime admixed with copper slag and tested after 7days, 14days and 28days of curing.

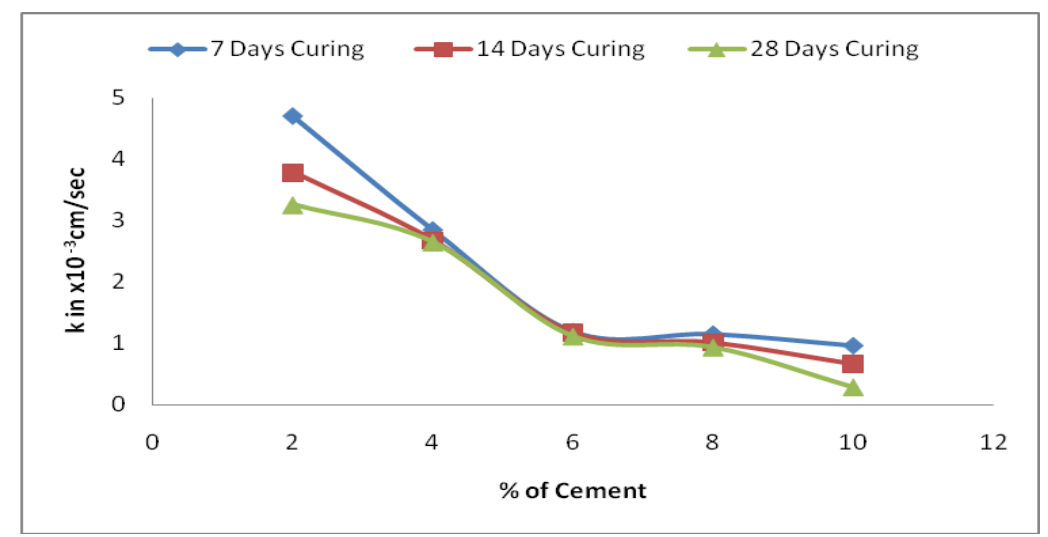

Fig. 2 Test results of Coefficient of Permeability for various \% of Cement admixed with copper slag and tested after 7days, 14days and 28days of curing. 
In fig 1 and fig 2 the variation is shown for the coefficient of permeability for various percentages of lime and cement admixed copper slag is tested after 7days, 14days and 28days of curing. From the figure it is seen that with increase in percentage of admixture there is a decrease in coefficient of permeability. From the results it is observed that the reduction in percentage of coefficient of permeability of copper slag when mixed with various $\%$ of admixture and tested after 7days, 14days and 28days of curing were ranging between $62 \%$ and $98 \%$ when compared with the copper slag alone.

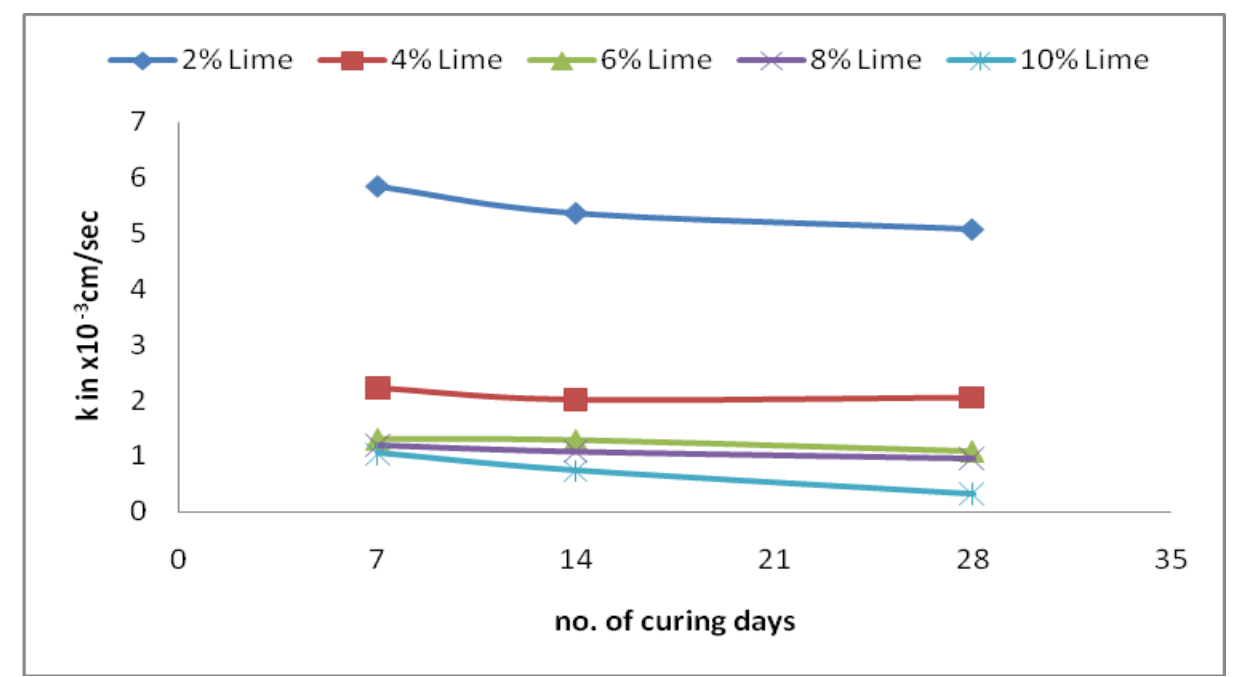

Fig. 3 Test results of Coefficient of Permeability Vs no. of curing days for various \% of Lime admixed with copper slag.

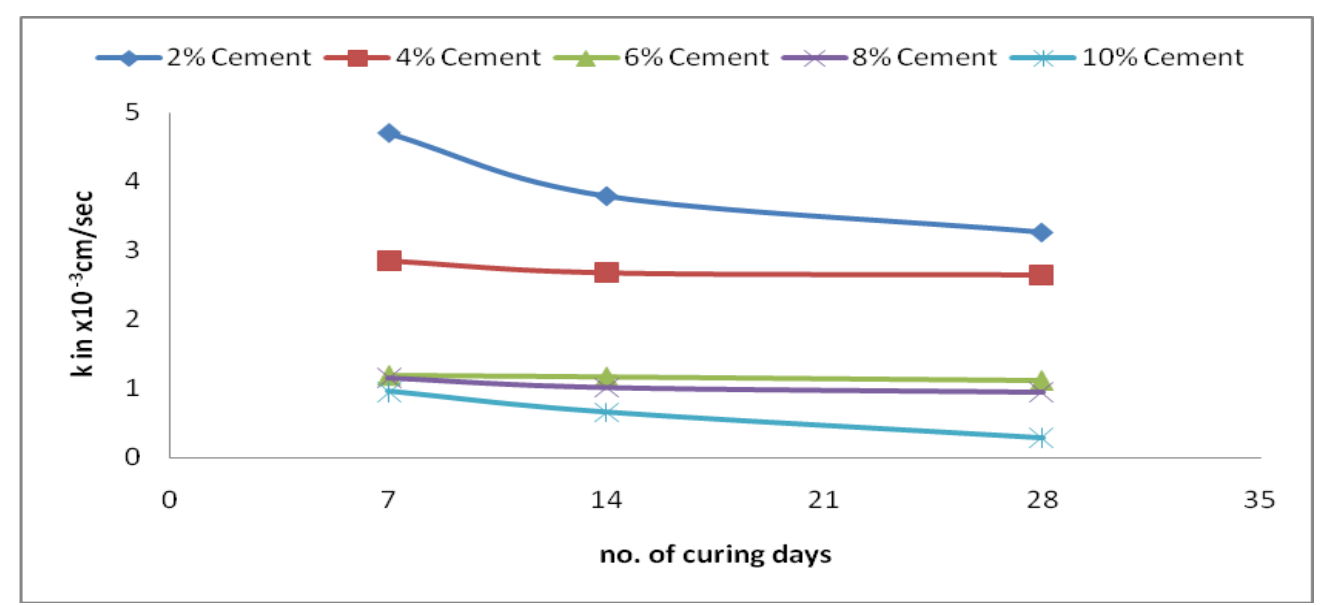

Fig. 4 Test results of Coefficient of Permeability Vs no. of curing days for various \% of Cement admixed with copper slag.

In fig 3 and fig 4 the variation is shown for the coefficient of permeability for various curing days of lime and cement admixed copper slag is tested for various percentages. With increase in no. of curing days of the copper slag admixed with lime and cement there is a decrease in coefficient of permeability. From the test results it is observed that the reduction in percentage of coefficient of permeability of copper slag when mixed with various $\%$ of lime and cement range differently with the percentage and with curing period. For $2 \%$ and $10 \%$ lime or cement the percentage reduction of permeability is between $4 \%$ and $5 \%$ from 7 days to 28 days of curing period. Whereas for $4 \%, 6 \%, 8 \%$ lime or cement the percentage reduction of permeability is between $1 \%$ and $2 \%$ from 7 days to 28 days of curing period. 


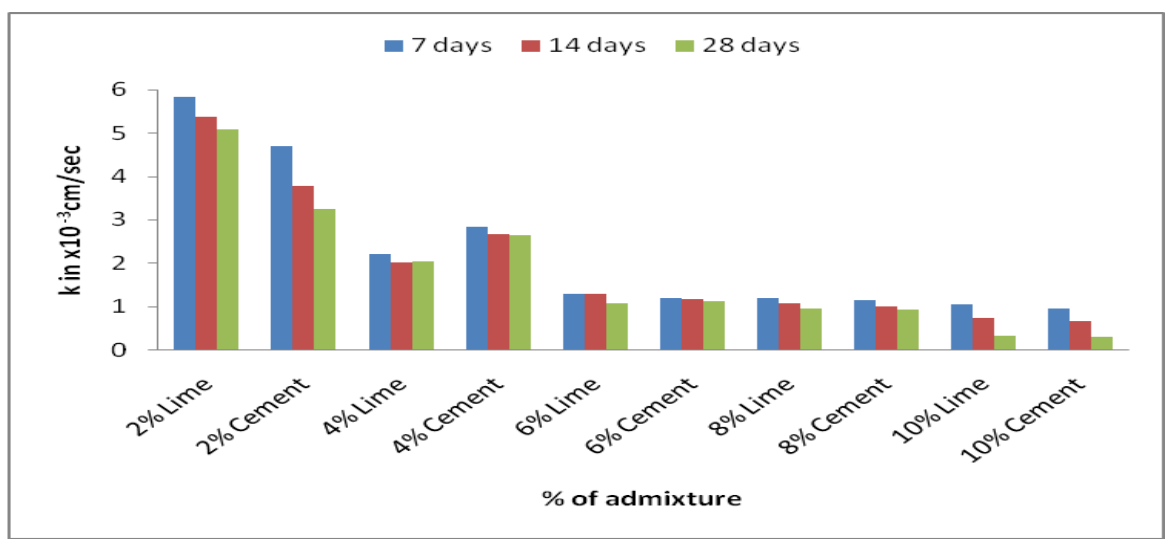

Fig. 5 Test results of Coefficient of Permeability for various \% of lime and cement admixed with copper slag and tested after 7days, 14days and 28days of curing.

In fig 5 the variation is shown for the coefficient of permeability for various $\%$ of lime and cement admixed with copper slag and tested after 7days, 14days and 28days of curing. From the figure, it is seen that there is a decrease in coefficient of permeability with the increase in percentage of admixture and also with increase in curing period.

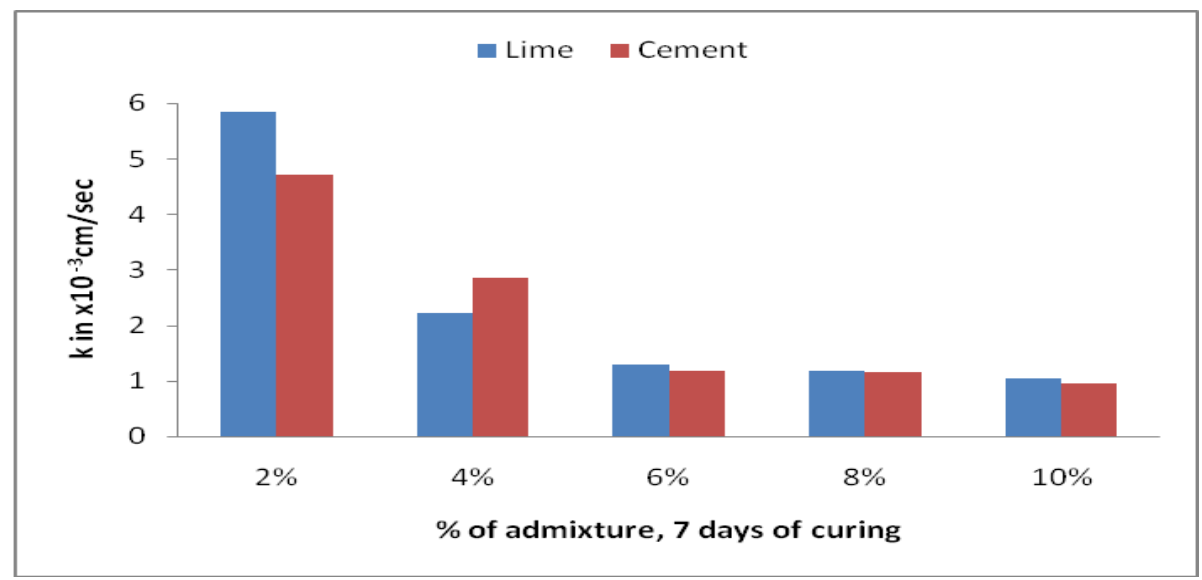

Fig. 6 Test results of Coefficient of Permeability for various \% of Cement and Lime admixed with copper slag and tested after 7 days of curing.

In fig 6 the variation is shown for the coefficient of permeability for various $\%$ of lime and cement admixed with copper slag and tested after 7 days of curing. From the test results it is observed that the reduction in percentage of coefficient of permeability of copper slag when compared to that of copper slag alone is between $62 \%$ and $93 \%$ for $2 \%$ to $10 \%$ lime respectively for 7 days of curing period whereas for cement it ranges between $69.5 \%$ and $94 \%$.

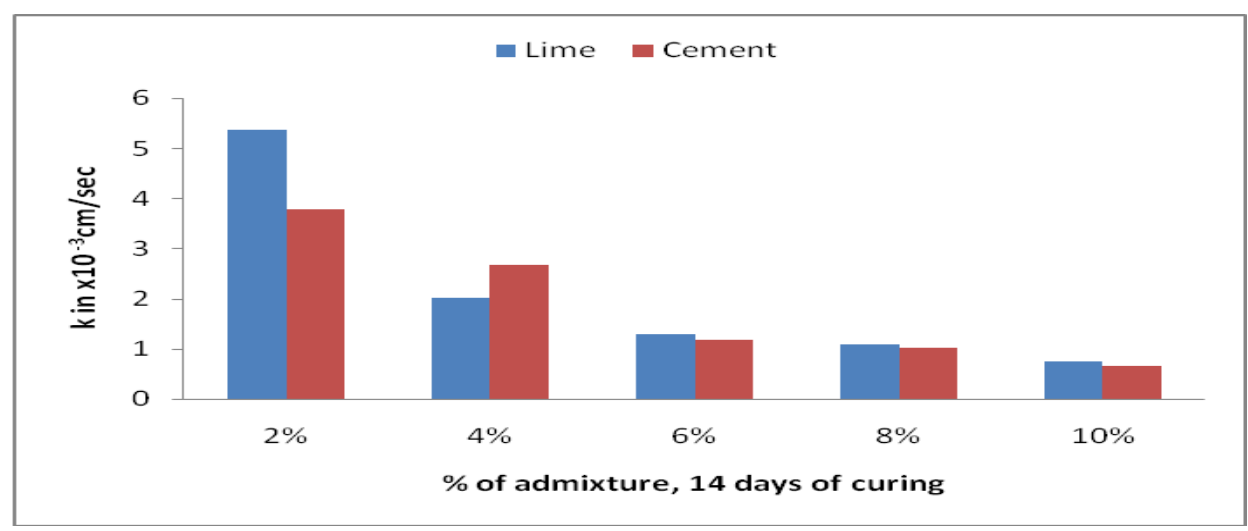

Fig. 7 Test results of Coefficient of Permeability for various \% of Cement and Lime admixed with copper slag and tested after 14 days of curing. 
In fig 7 the variation is shown for the coefficient of permeability for various $\%$ of lime and cement admixed with copper slag and tested after 14days of curing. From the test results it is observed that the reduction in percentage of coefficient of permeability of copper slag when compared to that of copper slag alone is between $65 \%$ and $95 \%$ for $2 \%$ to $10 \%$ lime respectively for 7 days of curing period whereas for cement it ranges between $75 \%$ and $95.5 \%$.

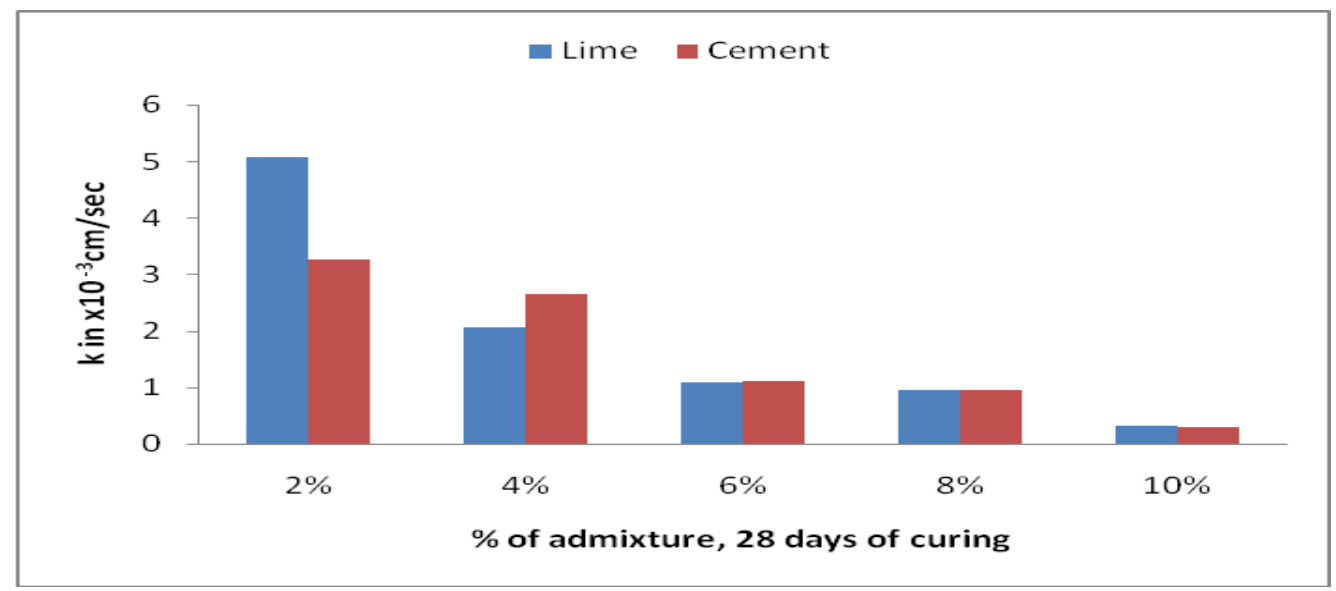

Fig. 8 Test results of Coefficient of Permeability for various \% of Cement and Lime admixed with copper slag and tested after 28 days of curing.

In fig 8 the variation is shown for the coefficient of permeability for various $\%$ of lime and cement admixed with copper slag and tested after 28days of curing. From the test results it is observed that the reduction in percentage of coefficient of permeability of copper slag when compared to that of copper slag alone is between $67 \%$ and $98 \%$ for $2 \%$ to $10 \%$ lime respectively for 7 days of curing period whereas for cement it ranges between $79 \%$ and $98 \%$.

In fig 6 , fig 7 and fig 8 the variation is shown for the coefficient of permeability for various $\%$ of lime and cement admixed with copper slag and tested after 7days, 14days and 28days of curing. From the figures, it is seen that there is a decrease in coefficient of permeability with the increase in percentage of cement as an admixture when compared to that of lime. But for $4 \%$ admixture there is an increase in coefficient of permeability value for cement when compared with lime as an admixture.

\section{Conclusions}

Based on the above variable head permeability test results of copper slag mixed with lime or cement the below are the outlines presented.

1. Lime and cement are used as a binding material to the copper slag to reduce the coefficient of permeability.

2. Lime mixed Copper slag in various percentages gives effective and improved results of coefficient of permeability when compared with the copper slag alone. As the $\%$ of lime increases from $2 \%$ to $10 \%$ the there is a decrease in coefficient of permeability. From the results, it was noticed that a decrease in coefficient of permeability is even with the number of curing days from 7 to 28 .

3. Percentage decrease of coefficient of permeability is from $62 \%$ to $98 \%$ for the copper slag mixed with lime of varying percentage from $2 \%$ to $10 \%$ after curing for 7 to 28 days.

4. Cement mixed Copper slag in various percentages also gives effective results of coefficient of permeability when compared with the copper slag alone. As the $\%$ of cement increases from $2 \%$ to $10 \%$ the there is a decrease in coefficient of permeability. From the results, it was also noticed that a decrease in coefficient of permeability is even with the number of curing days from 7 to 28 as that of lime.

5. Percentage decrease of coefficient of permeability is from $69 \%$ to $98 \%$ for the copper slag mixed with cement of varying percentage from $2 \%$ to $10 \%$ after curing for 7 to 28 days.

6. When Lime or cement is mixed with copper slag along with expansive soils may be advantageous in terms of stabilization.

7. As a future study, copper slag as one of the waste material along with binding material either lime or cement and expansive soil can be mixed and important geotechnical testing can be carried out to bring out the effectiveness of copper slag in the soil stabilization process. 


\section{References}

[1] Hartlen, J., Carling, M \& Nagasaka, Y. (1997) Recycling or reuse of waste materials in geotechnical applications, Proceedings of the second International Congress on Environmental Geotechnics, Osaka, Japan, pp 1493-1513.

[2] Kamon, M. (1997) Geotechnical utilization of industrial wastes, Proceedings of the second International Congress on Environmental Geotechnics, Osaka, Japan, pp 1293-1309.

[3] Kamon, M. \& Katsumi, T. (1994) Civil Engineering use of industrial waste in Japan, Proceedings of the International Symposium on Developments in Geotechnical Engineering, Bangkok, Thailand, pp 265-278.

[4] Sarsby, R. (2000) Environmental Geotechnics, Thomas Telford Ltd., London, UK.

[5] Vazquez, E., Roca, A., Lopez-soler, A., Fernandez-Turiel, J.L., Querol, X \& Felipo, M.T. (1991) Physico-Chemical and mineralogy characterization of mining wastes used in construction, Waste materials in construction, Proceedings of the International Conference on Environmental Implications of Construction with Waste Materials, Maastricht, The Netherlands, pp 215-223.

[6] Comans, R.N.J., van det Sloot, H.A., Hoede, D. \&Bonouvrie, P.A. (1991) Chemical Processes at a redox/pH interface arising from the use of steel slag in the aquatic environment, Waste materials in construction, Proceedings of the International Conference on Environmental Implications of Construction with Waste Materials, Maastricht, The Netherlands, pp 243-254.

[7] Chu, S.C. and Kao, H.S. (1993) A study of Engineering Properties of a clay modified by Fly ash and Slag, Proceedings, Fly ash for Soil Improvement, American Society of Civil Engineers, Geotechnical Special Publication, No. 36, pp 89 - 99.

[8] Mclaren, R.J. and A.M.Digionia, (1987) The typical engineering properties of fly ash, Proceedings of Conference on Geotechnical Practice for Waste Disposal, Geotechnical Special Publication NO 13, ASCE, R.D.Woods (ed.), pp 683-697.

[9] Martin, P.J., R.A.Collins, J.S.Browning and J.F.Biehl, (1990) Properties and use of fly ashes for embankments, Journal of Energy Engineering, ASCE, 116(2), pp 71-86.

[10] IS: 2720 (part-17) (1966), "Laboratory Determination of Permeability", Bureau of Indian Standards. 